\title{
Pengelompokan dan Peramalan Deret Waktu pada Produksi Bawang Merah Tingkat Provinsi di Indonesia
}

\author{
(Clustering and Forecasting for Shallot Production Time Series \\ at Provincial Level in Indonesia)
}

\author{
Rifqi Aulya Rahman ${ }^{1 *}$, Farit Mochamad Afendi ${ }^{1}$, Widhiyanti Nugraheni ${ }^{2}$, Kusman Sadik $^{1}$, Akbar Rizki $^{1}$ \\ ${ }^{1}$ Departemen Statistika, Institut Pertanian Bogor \\ ${ }^{2}$ Direktorat Jenderal Hortikultura, Kementerian Pertanian \\ Jalan Meranti Wing 22 Level 4 Kampus IPB, Dramaga, Bogor \\ E-mail: rifqiaulya@apps.ipb.ac.id
}

\begin{abstract}
ABSTRAK
Bawang merah adalah komoditas strategis negara yang dapat memengaruhi ekonomi nasional. Setiap tahun, produksi bawang merah meningkat beriringan dengan konsumsi rumah tangga. Setiap provinsi memiliki pola produksi berbedabeda pada jumlah dan deret waktu panen. Penelitian ini bertujuan untuk menentukan kelompok-kelompok deret waktu dan memberi evaluasi terhadap peramalan produksi tingkat provinsi dan kelompok. Deret-deret waktu dikelompokkan secara hirarki dengan metode agglomerative melalui pautan rataan jarak Euclidean. Jumlah kelompok optimal ditinjau menurut grafik Elbow. Kemudian, setiap provinsi dimodelkan Autoregressive Integrated Moving Average (ARIMA) dan Seasonal ARIMA (SARIMA) untuk peramalan tingkat provinsi. Kelompok-kelompok deret waktu yang terbentuk juga dibangun model sehingga hasil peramalan kedua tingkat dibandingkan dan dievaluasi. Sebanyak tiga kelompok optimal terbentuk memiliki karakteristik pola deret dan produksinya yakni trend naik musiman, trend naik dan trend turun. Pengelompokan ini membuat peramalan menjadi lebih efisien. Hal ini berdasarkan rata-rata Mean Absolute Percentage Error (MAPE) tingkat kelompok lebih kecil daripada tingkat provinsi.
\end{abstract}

Kata kunci: Pengelompokan, Deret Waktu, Bawang Merah

\begin{abstract}
Shallots are strategic vegetable commodity state that can affect the national economy. Shallots production increases every year that in line with domestic household consumption. Every province in Indonesia has a different level of shallot production, both in terms of cycles and harvest amount. Clustering provinces with similar production patterns can help government policies. This research aims to determine cluster time series and to evaluate the shallot production forecast in several provinces in Indonesia. There are three of optimal clusters which have a characteristic pattern in time series and their production. Time series at provincial level and cluster level, then it is modelled based on Autoregressive Integrated Moving Average (ARIMA) and Seasonal ARIMA (SARIMA). The evaluation of cluster level is compared to the provincial level and is concluded that clustering makes forecasting efficiently. This is based on average of Mean Absolute Percentage Error (MAPE) that is smaller than provincial level.
\end{abstract}

Keywords: Clustering, Time Series, Shallot

\section{PENDAHULUAN}

Produksi komoditas bawang merah secara nasional selalu mengalami trend naik setiap tahunnya. Statistik hortikultura mencatat pada tahun 2019 produksi bawang merah naik sebesar 5,11\% atau senilai 76,8 ribu ton dibandingkan dengan tahun 2018. Rencana Strategis Kementerian Pertanian tahun 2020 hingga 2024 menargetkan peningkatan produksi sayuran seperti bawang merah naik $2.7 \%$ pada tahun 2021 (Kementerian Pertanian, 2020). Target ini diharapkan sejalan dengan produksi tiap provinsi di Indonesia karena statistik mencatat kebutuhan rumah tangga terhadap komoditas ini selalu meningkat. Setiap provinsi memiliki kondisi produksi bawang merah yang berbeda-beda dalam hal jumlah produksi. Hal ini menyebabkan distribusi produksi bawang merah tidak merata di Indonesia. Contoh kasus ini terlihat pada analisis integrasi spasial oleh Kustiari (2017) yang menyatakan bahwa antar provinsi penghasil bawang merah terbesar memiliki ketergantungan sistem pemasaran terhadap provinsi yang minim produksi bawang merah. Sebagai tambahan, bawang merah adalah salah satu komoditas pertanian yang memengaruhi inflasi (Kementerian Pertanian, 2015). Tiga provinsi penyumbang bawang merah terbesar yakni Jawa Tengah, Jawa Timur dan Nusa Tenggara Barat (BPS, 2019). Ketika harga bawang merah mengalami kenaikan di provinsi tersebut, maka hal ini dapat mengganggu perekonomian nasional. Selain perbedaan produksi tiap provinsi, masa panen yang berbeda beda juga dapat menimbulkan kondisi kenaikan dan kelangkaan di provinsi-provinsi yang minim produksi. 
Pemerintah memiliki peran untuk membuat kebijakan dalam pengendalian dan mencapai target produksi bawang merah tingkat provinsi hingga nasional. Karakteristik produksi tiap provinsi berbeda-beda, sehingga sangat rumit dalam manajemen kebijakan ketika mengamati satu per satu provinsi. Pengelompokan provinsiprovinsi berdasarkan karakteristik produksi bawang merah dapat membuat manajemen kebijakan lebih efisien. Karakteristik yang dimaksud mencakup ukuran jumlah dan pola deret waktu produksi bawang merah. Pembentukan kelompok juga membuat pemodelan deret waktu lebih efektif daripada membuat model untuk setiap unit atau provinsi (Hendrawati et al., 2021). Pertanyaan yang muncul dalam penelitian ini bagaimana mengelompokan provinsi-provinsi terhadap ukuran produksi bawang merah baik dari segi ukuran dan deret waktu. Setelah itu, perhatian selanjutnya adalah bagaimana kelompok-kelompok tersebut dapat menjadi model dalam memprediksi produksi bawang merah pada satu bulan atau satu tahun kedepan sebagai bahan target.

Penelitian ini bertujuan untuk menentukan kelompok-kelompok deret waktu produksi bawang merah dan melakukan evaluasi peramalan terhadap tingkat provinsi dan tingkat kelompok. Data diperoleh dari Direktorat Jenderal Hortikultura Kementerian Pertanian berupa produksi bawang merah dalam kurun tahun 2015-2020 untuk setiap provinsi di Indonesia. Namun, tidak semua provinsi akan menjadi objek penelitian karena data perlu dibersihkan. Provinsi-provinsi dengan penghasil terkecil dan nilai produksi nihil pada suatu tahun tidak diikutsertakan. Kemudian, antar deret waktu dihitung ukuran kedekatannya menggunakan jarak Euclidean sampai terbentuk matriks jarak. Ukuran ini sering dan mudah digunakan pada pengelompokan deret waktu (Maharaj et al., 2019). Jarak Euclidean mampu mengukur kemiripan titik-titik antara dua deret waktu dalam hal nilai produksi bawang merah agar terbentuk kelompok nilai-nilai besar dan kecil. Kemudian, Indonesia tidak memiliki informasi berapa banyak jenis kelompok provinsi dalam acuan pengelompokan. Untuk itu, metode pengelompokan hirarki secara agglomerative mampu mengatasi hal tersebut (T.Kousiga \& Dr. $\mathrm{R}$ Shanmuga Vadiv, 2019). Pengelompokan dengan metode ini dimulai dengan menganggap provinsi-provinsi sebagai kelompok berbeda kemudian diukur kedekatan jaraknya dengan pautan rataan hingga seluruh provinsi terhimpun satu kelompok. Pautan rataan memiliki keuntungan karena nilai rata-rata dapat menjadi interpretasi dari suatu kelompok karena berbentuk kalkulasi setiap objek. Hasil dari metode ini adalah pohon dendogram yang tersusun atas kelompok-kelompok provinsi dengan jumlah kelompok optimal pada observasi grafik Elbow (Shi et al., 2021).

Peramalan dapat dilakukan pada dua tingkat, yakni provinsi (unit) atau kelompok. Model deret waktu Autoregressive Integrated Moving Average (ARIMA) dapat memahami data historis deret waktu, mengidentifikasi parameter global model dan meramalkan nilai-nilai untuk beberapa waktu kedepan (Montgomery et al., 2015). Pengembangan dari ARIMA untuk tipe waktu musiman disebut Seasonal ARIMA (SARIMA). Deret-deret waktu produksi bawang merah tingkat provinsi kemudian dimodelkan dan dilakukan proses peramalan pada data uji tahun 2020. Selain itu, model juga diterapkan pada prototipe tingkat kelompok. Selanjutnya, diukur kesalahan peramalan dengan memperhatikan nilai Mean Absolute Percentage Error (MAPE) pada kedua tingkat provinsi dan kelompok (Wijaya \& Ngatini, 2020). Harapan penelitian ini adalah nilai MAPE tingkat kelompok lebih kecil daripada tingkat provinsi, sehingga selain pengelompokan menjadi efisien dalam kebijakan juga efektif dalam peramalan.

\section{METODE}

\section{Data dan Sumber Data}

Data yang dikaji pada penelitian ini, yaitu produksi bawang merah dalam satuan kuintal untuk setiap provinsi di Indonesia yang diamati setiap bulan dalam kurun tahun 2015-2020. Jumlah observasi data sebanyak 72 untuk setiap 34 provinsi. Data ini diperoleh dari statistik produksi sayuran Direktorat Jenderal Hortikultura Kementerian Pertanian.

\section{Analisis Data}

Prosedur analisis data diuraikan sebagai berikut.

1. Menerangkan eksplorasi dari produksi bawang merah pada 34 provinsi. Kemudian, mengeliminasi provinsi-provinsi yang terdapat nilai produksi nihil pada tahun tertentu.

2. Memisah data deret menjadi dua bagian yakni data latih dan uji. Data latih adalah 60 observasi pertama dan data uji sebanyak 12 observasi terakhir (tahun 2020).

3. Melakukan pengelompokan hirarki pautan rataan dengan proses sebagai berikut.

a. Melakukan standarisasi nilai pada setiap deret waktu dengan kaidah Z-Score.

b. Membentuk matriks jarak antar deret waktu antar provinsi. Perhitungan jarak Euclidean sebagai 


$$
d_{i l}=\sqrt{\sum_{j=1}^{J}\left(x_{i j}-x_{l j}\right)^{2}}
$$

dengan $d_{i l}$ adalah jarak Euclidean antara deret ke- $i$ terhadap deret ke- $l$ untuk setiap nilai observasi $x_{i j}$ dan $x_{l j}$ periode ke $j=1$ hingga $j=J$ atau panjang dari suatu deret waktu (Maharaj et al., 2019).

c. Melakukan pengelompokan dimulai dari penetapan provinsi-provinsi sebagai kelompok berbeda. Kemudian, memautkan provinsi-provinsi berdasarkan rata-rata jarak di antara kelompok dekat. Proses ini berakhir ketika setiap provinsi telah menjadi satu kelompok. Pohon dendogram adalah luaran dari tahap ini.

d. Penentuan jumlah kelompok optimal dilakukan secara observasi di titik siku kurva Elbow antara jumlah kelompok dengan sum of square error (SSE) (Shi et al., 2021).

4. Menentukan model ARIMA dan SARIMA pada deret waktu tingkat provinsi dengan proses berikut.

a. Memeriksa kestasioneran musiman dan tak musiman deret menggunakan plot Autocorrelation Function (ACF) dan uji Augmented Dickey Fuller Test (ADF). Dalam konteks ini, periode musiman didefinisikan dalam satu tahun. Jika model yang diperiksa tidak stasioner, maka akan distasionerkan melalui differencing atau pembedaan.

b. Mengidentifikasi ordo AR(p) berdasarkan plot Partial Autocorrelation Function (PACF), ordo MA(q) pada plot ACF, ataupun ARMA(p,q). Identifikasi ini juga dilakukan ketika terdapat ordo musiman yang signifikan atau SARIMA $(\mathrm{p}, \mathrm{d}, \mathrm{q})(\mathrm{P}, \mathrm{D}, \mathrm{Q})_{12}$. Pada langkah ini diperoleh kandidatkandidat model yang kemudian dipilih satu model terbaik dan layak mengacu pada nilai Akaike's Information Criterion (AIC) yang minimum, parameter yang signifikan, serta sisaan normal dan bebas.

5. Menentukan model deret waktu ARIMA atau SARIMA tingkat kelompok yang diwakili prototipe berupa rata-rata data pada suatu kelompok dengan proses seperti Langkah 4.

6. Memprediksi data uji serta menghitung nilai rata-rata persentase dari mutlak kesalahan (MAPE) tingkat provinsi dan kelompok.

7. Menjelaskan evaluasi hasil prediksi dan analisis kelompok.

\section{HASIL DAN PEMBAHASAN}

\section{Eksplorasi Data}

Setiap provinsi di Indonesia memiliki persentase kontribusi produksi bawang merah yang berbeda beda. Diagram pada Gambar 1 menunjukkan persentase rata-rata produksi setiap provinsi selama tahun 2015-2020. Setiap tahunnya provinsi dengan persentase penghasil bawang merah terbesar secara rata-rata secara berurutan adalah Jawa tengah, Jawa Timur, Nusa Tenggara Barat (NTB), Jawa Barat, Sulawesi Selatan, Sumatera Barat. Dalam hal ini, provinsi-provinsi tersebut telah menopang produksi bawang merah secara nasional sebesar $98,12 \%$. Selain provinsi dengan kontribusi terbesar, terdapat 16 provinsi selama kurun tahun tersebut yang konsisten memproduksi bawang merah dengan nilai amatan tak pernah nol. Sebagian provinsi tersebut berikutnya akan dilakukan analisis lebih lanjut. Kemudian, transformasi logaritma natural diterapkan pada amatan-amatan sebagian provinsi tersebut untuk mempermudah melakukan eksplorasi. Boxplot provinsiprovinsi tersebut disajikan pada Gambar 2. Berdasarkan gambar tersebut provinsi Papua Barat memiliki nilai produksi paling rendah di antara 16 provinsi. Sebagai catatan, beberapa provinsi terlihat memiliki nilai pencilan yang ekstrem diatas nilai maksimum dan dibawah nilai minimum.

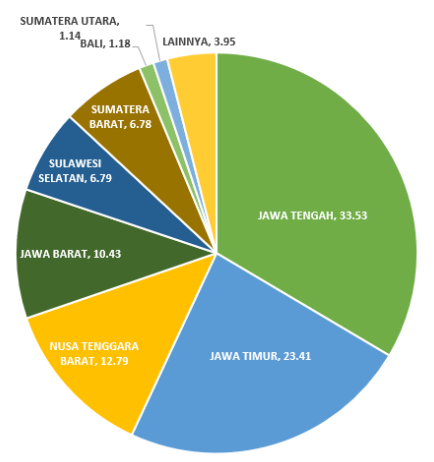

Gambar 1. Persentase Rata-Rata Produksi Setiap Provinsi (2015-2020) 


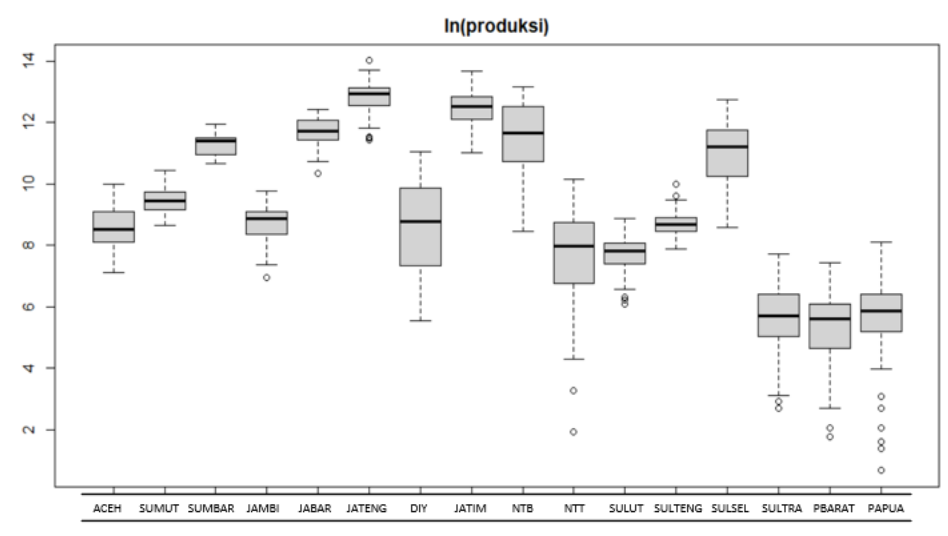

Gambar 2. Boxplot Logaritma Natural Produksi Sebagian Provinsi

Eksplorasi pola pergerakan bawang merah dilakukan dengan melihat pola plot deret waktu. Setiap provinsi menunjukkan plot yang berbeda, misalnya pada provinsi NTB yang terlihat pola musiman dan Sumatera Barat yang tidak stasioner dalam rataan, dalam hal ini nilainya terus menerus meningkat seperti terlihat pada Gambar 3. Provinsi yang secara observasi plot terlihat plot musiman yaitu NTB, Jawa Timur, Daerah Istimewa Yogyakarta (DIY), Jawa Barat, Nusa Tenggara Timur (NTT), Aceh, Sulawesi Selatan, Jawa Tengah dan Papua Barat.
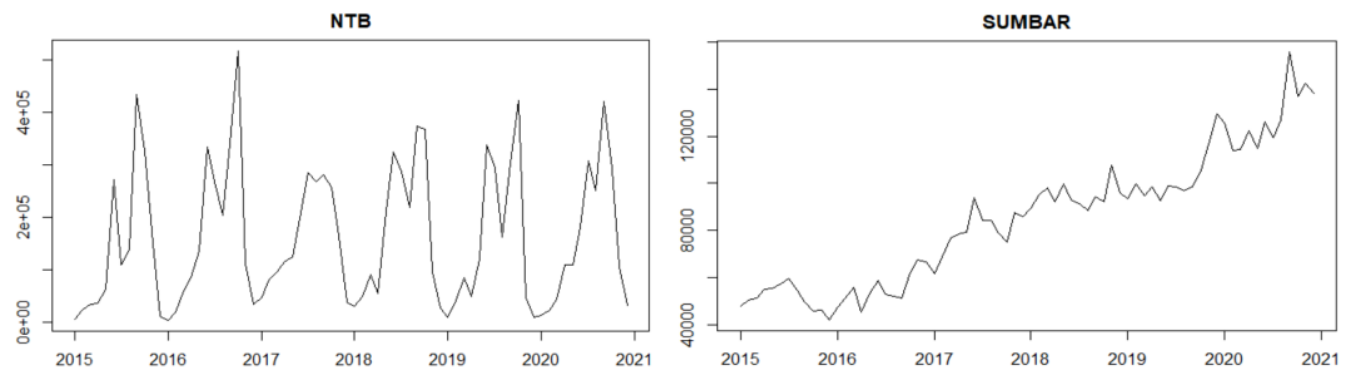

Gambar 3. Plot Produksi Provinsi NTB dan Sumatera Barat

Analisis musiman dilakukan untuk menjelaskan pola produksi dalam periode bulan dalam setahun. Provinsi NTB mengalami kenaikan produksi setelah pertengahan tahun, sedangkan Sulawesi Selatan menunjukkan penurunan pada rentang waktu itu. Berikut Gambar 4 yang menjelaskan kejadian tersebut.
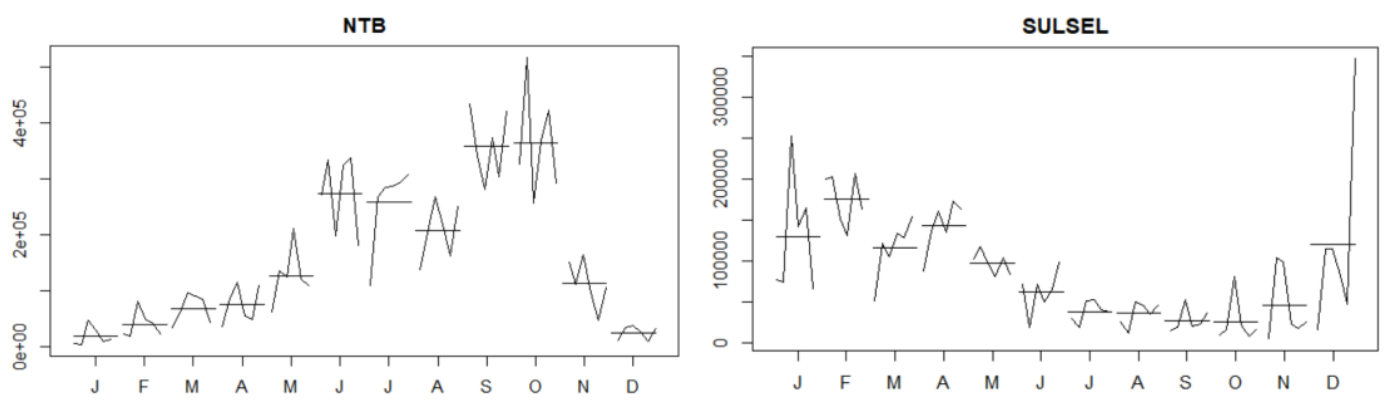

Gambar 4. Plot Musiman Provinsi NTB dan Sulawesi Selatan (SULSEL)

\section{Analisis Kelompok}

Setiap deret waktu di antara provinsi-provinsi dihitung kemiripan menggunakan jarak Euclidean sehingga membentuk matriks jarak. Perhitungan Euclidean sensitif terhadap data dengan skala yang beragam. Karena itu, nilai-nilai observasi terlebih dahulu dilakukan standarisasi menggunakan kaidah Z-score. Setelah itu, diterapkan metode pautan rataan untuk membentuk dendogram kelompok-kelompok secara agglomerative yang dapat dilihat pada Gambar 5. Jumlah kelompok optimal adalah tiga, karena merujuk titik siku pada kurva metode Elbow. Kelompok pertama adalah provinsi Jawa Timur, DIY, Aceh, dan NTT. Kelompok kedua yakni Sulawesi Tenggara, Jawa Barat, Jawa Tengah, Sulawesi Selatan, Papua Barat, Sulawesi Utara, Jambi, 
Sumatera Utara serta provinsi Sumatera Barat. Sementara itu, kelompok ketiga terdiri Sulawesi Tengah dan Papua. Peta ketiga kelompok digambarkan pada Gambar 6 dan kemiripan pola setiap kelompok disajikan pada Gambar 5. Kelompok pertama memiliki karakteristik pola musiman dengan trend naik yang terdiri provinsi produksi bawang merah yang tinggi. Kelompok kedua menunjukan anggota kelompok yang cenderung trend naik tanpa terlihat adanya pola musiman, namun terlihat potensi produksi meningkat menuju tahun 2020 . Kemudian, pada kelompok ketiga adalah deret-deret dengan trend turun. Kelompok ini berisi penurunan produksi yang kecil atau ekstrem mendekati tahun 2020. Untuk mempermudah pengenalan setiap karakteristik kelompok, maka ketiga kelompok selanjutnya akan diberi penamaan. Kelompok pertama diberi nama kelompok trend naik musiman, kedua yaitu trend naik, dan ketiga yakni kelompok trend turun.
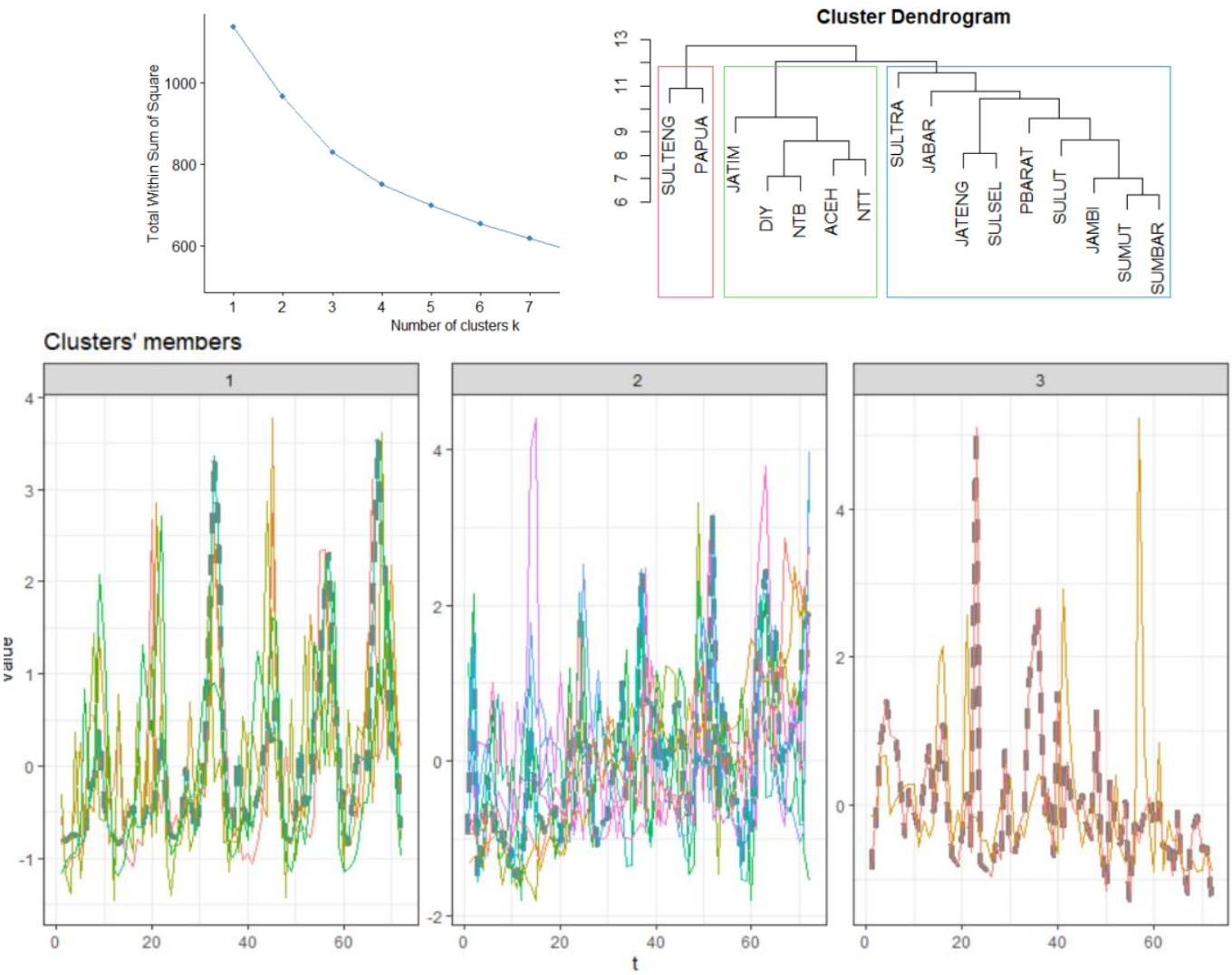

Gambar 5. Kurva Metode Elbow, Dendogram dan Pola Kelompok

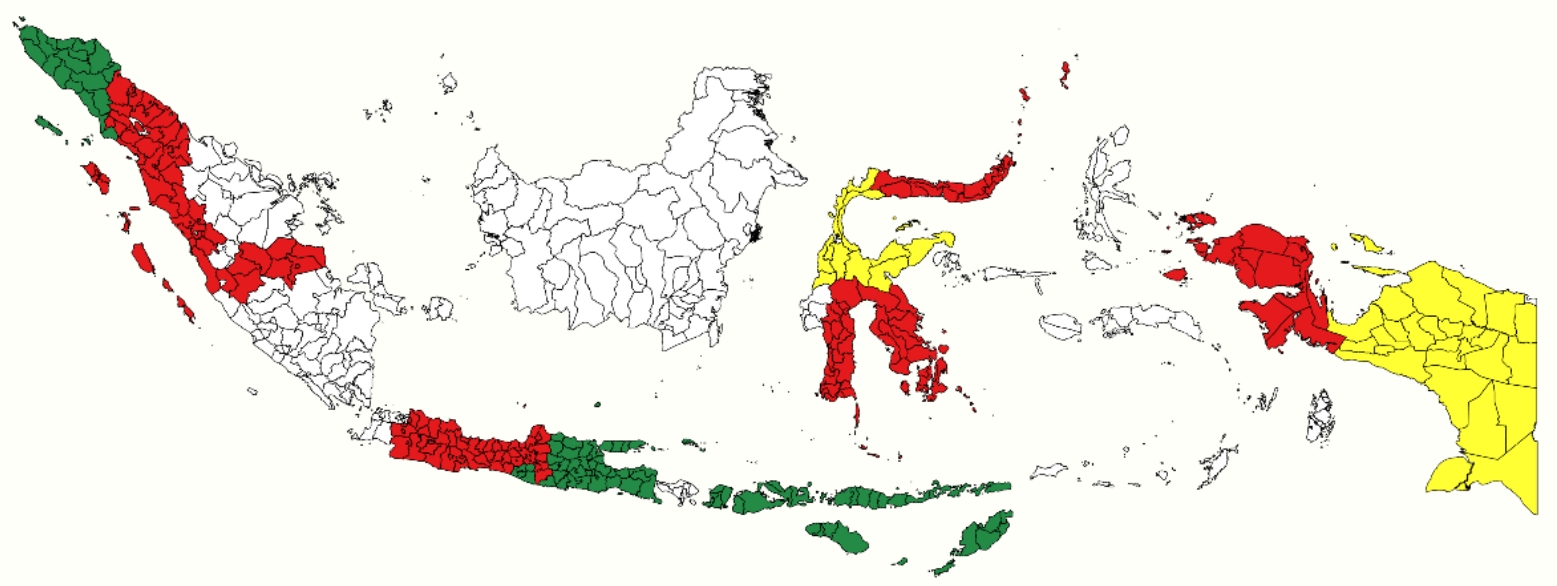

Gambar 6. Peta Kelompok Produksi Bawang Merah. Warna hijau adalah kelompok trend naik musiman. Warna merah adalah kelompok trend naik. Warna kuning adalah kelompok trend turun. 


\section{Pemodelan Tingkat Provinsi}

Pemodelan deret waktu tingkat provinsi dilakukan pada data latih sebanyak 60 observasi nilai produksi selama lima tahun dari Januari 2015 hingga Desember 2019 untuk keenam belas provinsi. Proses pembentukan model terlebih dahulu dengan memeriksa kestasioneran deret. Provinsi Sumatera Utara memiliki plot trend naik, artinya tidak stasioner dalam rataan. Hal ini dibuktikan oleh plot ACF pada Gambar 7 yang menurun perlahan, dan uji ADF yang menerima hipotesis null bahwa data tidak stasioner karena $p$-value $=0,18$ lebih besar dari taraf 0,05. Deret provinsi ini selanjutnya dilakukan pembedaan $d=1$ agar menjadi stasioner dan diperoleh plot ACF dan PACF yang terdapat pada Gambar 7. Plot ACF dan PACF tersebut menunjukkan pada lag 1 terjadi cut off, akibatnya terdapat dua kandidat model yakni ARIMA(0,1,1) dengan AIC sebesar 1151 dan ARIMA(1,1,0) dengan AIC sebesar 1156.
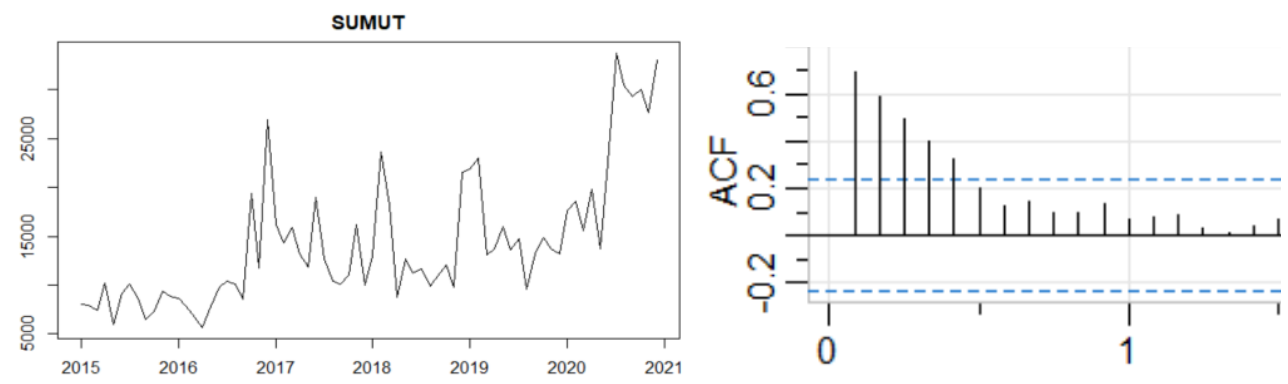

\section{Gambar 7. Plot Deret dan ACF SUMUT}

Model ARIMA $(0,1,1)$ dipilih untuk karena parameternya yang signifikan dan memiliki nilai AIC yang lebih kecil. Selanjutnya adalah pemeriksaan sisaan dari model ARIMA $(0,1,1)$. Gambar 8 menyatakan bahwa sisaan berdistribusi normal serta bebas yang masing-masing menurut plot kuantil-kuantil normal mendekati garis lurus dan $p$-value dari Ljung Box diatas garis uji.

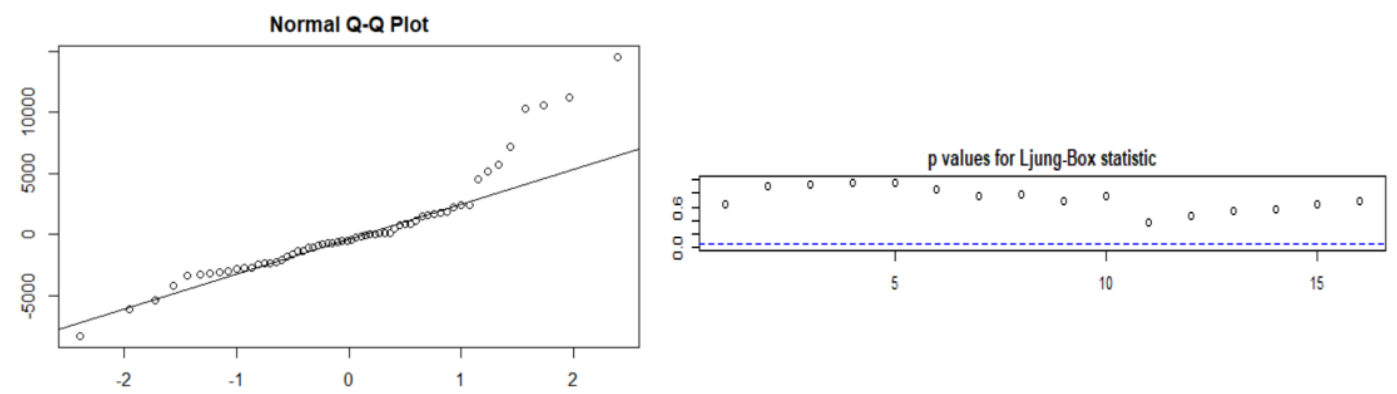

Gambar 8. Plot Kuantil-Kuantil dan p-value Ljung Box

Identifikasi model tak musiman pada data Aceh yakni ARIMA(1,0,0). Berikutnya, ditemukan cut off plot ACF di lag 12, sehingga deret waktu Aceh memiliki model musiman SARIMA $(1,0,0)(0,0,1)_{12}$. Pengecekan sisaan juga dilakukan dan diketahui berdistribusi normal dan bersifat bebas. Sesudah itu, setiap provinsi dikonstruksi model secara satu persatu yang disimpulkan pada Tabel 1.

Tabel 1. Model Setiap Provinsi

\begin{tabular}{cccc}
\hline Provinsi & ARIMA/SARIMA & Provinsi & ARIMA/SARIMA \\
\hline Sumatera Utara & $(0,1,1)$ & Jawa Barat & $(0,0,0)(0,0,1)_{12}$ \\
Sumatera Barat & $(2,1,1)$ & Jawa Tengah & $(0,0,3)(0,0,1)_{12}$ \\
Sulawesi Utara & $(0,1,1)$ & DIY & $(1,0,0)(1,1,0)_{12}$ \\
Sulawesi Tengah & $(2,0,2)$ & Jawa Timur & $(2,0,2)(0,0,1)_{12}$ \\
Sulawesi Tenggara & $(2,1,2)$ & NTB & $(1,0,1)(0,1,1)_{12}$ \\
Papua & $(2,0,2)$ & NTT & $(0,0,2)(0,0,2)_{12}$ \\
Aceh & $(1,0,0)(0,0,1)_{12}$ & Sulawesi Selatan & $(1,0,0)(1,1,0)_{12}$ \\
Jambi & $(0,1,1)(0,0,1)_{12}$ & Papua Barat & $(0,1,1)(0,0,1)_{12}$ \\
\hline
\end{tabular}




\section{Pemodelan Tingkat Kelompok}

Pemodelan tingkat kelompok dilakukan sama seperti tingkat provinsi, namun menggunakan prototipe yang diwakili rata-rata deret dari suatu kelompok. Prototipe tersebut kemudian dimodelkan terhadap model ARIMA/SARIMA sehingga untuk setiap kelompok menghasilkan rincian identifikasi model pada Tabel 2.

Tabel 2. Model Setiap Kelompok

\begin{tabular}{cc}
\hline Kelompok & ARIMA/SARIMA \\
\hline Kelompok trend naik musiman & $(1,0,0)(1,1,0)_{12}$ \\
Kelompok trend naik & $(0,0,1)(0,1,0)_{12}$ \\
Kelompok trend turun & $(2,0,2)$ \\
\hline
\end{tabular}

Kelompok trend naik musiman memiliki prototipe dengan karakteristik tidak stasioner pada musiman, dalam hal ini produksi bawang merah memiliki masa panen terus meningkat produksinya setiap musim atau tahuntahun terakhir. Untuk itu, model yang terbentuk signifikan pada parameter musiman (SARIMA). Masa panen kelompok ini terjadi diatas pertengahan tahun yakni mulai meningkat bulan Juni dan turun di November. Kemudian, kelompok trend naik mempunyai karakteristik prototipe cenderung meningkat. Anggota kelompok ini sebagian besar mempunyai masa panen di awal tahun yaitu mulai naik pada bulan Januari dan turun di bulan Juni. Pada kelompok trend turun, model yang terbentuk stasioner pada rataan namun pada plot terlihat keragaman data yang cukup besar dan ekstrim.

\section{Evaluasi Peramalan}

Peramalan tingkat provinsi dilakukan pada data uji sebanyak 12 observasi nilai produksi selama satu tahun dari Januari 2020 hingga Desember 2020 untuk keenam belas provinsi. Nilai kesalahan ramalan kemudian dikalkulasi melalui formula MAPE. Model dengan kesalahan yang besar ketika lebih dari 0,50 karena memiliki kinerja peramalan yang kurang baik. Untuk itu, model tak musiman dilakukan pengujian kembali pada satu waktu kedepan saja yakni Januari 2020. Peramalan dengan kesalahan paling kecil terjadi pada model provinsi Sumatera Barat yakni 0,08, artinya model sangat cukup baik memprediksi bawang merah pada tahun 2020. Namun, menurut Tabel 3, ada empat provinsi dengan kesalahan peramalan yang besar pada tingkat provinsi yakni Sulawesi Tengah, Sulawesi Tenggara, Papua, dan Nusa Tenggara Timur. Hal ini dikarenakan, pada data-data uji mengandung nilai yang ekstrem sehingga model ARIMA atau SARIMA yang bersifat stasioner pada rataan sukar untuk meramal dengan tepat, misalnya provinsi Papua pada tahun 2020 terjadi penurunan produksi sebesar $193 \%$ dari tahun sebelumnya.

Tabel 3. Peramalan Tingkat Provinsi

\begin{tabular}{ccccc}
\hline Provinsi & MAPE 2020 & Provinsi & MAPE 2020 & MAPE DES 2020 \\
\hline Aceh & 0,39 & Sulawesi Selatan & 0,32 & - \\
Jambi & 0,29 & Papua Barat & 0,39 & - \\
Jawa Barat & 0,33 & Sumatera Utara & 0,39 & 0,17 \\
Jawa Tengah & 0,25 & Sumatera Barat & 0,08 & 0,03 \\
DIY & 0,49 & Sulawesi Utara & 0,46 & 0,29 \\
Jawa Timur & 0,25 & Sulawesi Tengah & 0,52 & 1,25 \\
NTB & 0,43 & Sulawesi Tenggara & 1,05 & 0,33 \\
NTT & 0,63 & Papua & 48,3 & 126,88 \\
\hline
\end{tabular}

Peramalan pada tingkat kelompok yang dapat menjadi alternatif karena dapat menurunkan nilai MAPE tahun 2020 pada provinsi Sulawesi Tengah menjadi 0,34 dan provinsi Papua juga turun menjadi 0,97. Selain itu, ketika dilakukan peramalan pada skala nasional, diperoleh penurunan rata-rata MAPE tahun 2020 sebesar 43\% dari peramalan tingkat provinsi. Dalam hal ini, peramalan tingkat kelompok lebih efisien daripada tingkat provinsi. Berikutnya, model tingkat kelompok dilakukan prediksi terhadap produksi bawang merah tahun 2021. Hasil yang diperoleh yaitu terjadi kenaikan produksi bawang merah sebesar $1,96 \%$ atau setara 35,18 ribu ton dari tahun 2020 dengan total produksi sebanyak 1791,62 ribu ton. Dengan demikian, keenam belas provinsi pada penelitian ini diramalkan akan mencapai target $72 \%$ dari target nasional. 


\section{KESIMPULAN}

Penelitian ini menemukan tiga kelompok optimal yang dapat meringkas enam belas provinsi yakni kelompok trend naik musiman, trend naik, dan trend turun. Kelompok trend naik musiman yaitu provinsi Jawa Timur, DIY, Aceh, dan NTT. Kelompok ini memiliki ciri khas provinsi-provinsi dengan pola trend produksi musiman yang meningkat setiap tahun dan dengan jumlah produksi besar. Masa panen kelompok ini diatas pertengahan tahun. Kemudian, kelompok trend naik yakni Sulawesi Tenggara, Jawa Barat, Jawa Tengah, Sulawesi Selatan, Papua Barat, Sulawesi Utara, Jambi, Sumatera Utara serta Sumatera Barat. Anggota kelompok ini cenderung memiliki trend naik tanpa terlihat adanya pola musiman, namun terlihat potensi produksi meningkat pada tahun selanjutnya pada kelompok ini. Kelompok ini mempunyai masa panen di awal tahun. Selanjutnya, kelompok trend turun yaitu Sulawesi Tengah dan Papua. Kedua provinsi ini memiliki keragaman nilai yang besar dan penurunan produksi yang ekstrem.

Berdasarkan analisis kelompok, pemerintah dapat membuat strategi kebijakan lebih efektif dan mengendalikan distribusi bawang merah ke depan. Pemerintah juga dapat lebih spesifik untuk membuat kebijakan terhadap suatu kelompok provinsi yang memiliki ciri khas produksi dan pola panen tertentu. Selain itu, kelompok trend naik musiman dan kelompok trend naik dapat bergantian untuk memasok kebutuhan bawang merah nasional saat terjadi kelangkaan karena periode panen yang berbeda. Kemudian, pemerintah perlu memberi perhatian khusus pada kelompok trend turun agar dapat dicari permasalahan penurunan produksi. Selain keenam belas provinsi yang diteliti, peneliti mengharapkan pemerintah untuk tetap memaksimalkan usaha peningkatan produksi bawang merah agar setiap provinsi dapat mandiri.

Pengelompokan provinsi-provinsi produksi bawang merah di Indonesia dapat menjadi alternatif pada peramalan skala nasional karena lebih efisien. Hal ini dikarenakan tingkat kesalahan yang lebih rendah. Berdasarkan evaluasi peramalan penelitian ini, provinsi dengan model musiman memiliki performa yang baik ketika meramal satu tahun kedepan, sedangkan provinsi dengan model tak musiman lebih baik ketika meramal satu bulan kedepan. Provinsi dengan model tak musiman untuk tingkat kesalahan ramalan MAPE paling kecil adalah Sumatera Barat. Selain itu, provinsi dengan model musiman dalam peramalan yang memiliki MAPE paling kecil adalah Jawa Tengah dan Jawa Timur. Akan tetapi, beberapa provinsi seperti Papua, NTT, Sulawesi Tengah dan Sulawesi Tenggara memiliki kelemahan pada pemodelan karena data uji yang mengandung nilai ekstrem. Penelitian selanjutnya diharapkan dapat mengatasi pengelompokan deret waktu dengan data yang mengandung nilai ekstrem.

\section{DAFTAR PUSTAKA}

BPS. (2019). Statistik Hortikultura. Badan Pusat Statistik.

Kementerian Pertanian. (2020). Rencana Strategis Kementerian Pertanian Tahun 2020-2024. Kementerian Pertanian.

Kementerian Pertanian. (2015). Rencana Strategis Kementerian Pertanian Tahun 2015-2019. Kementerian Pertanian.

Hendrawati, T., Wigena, A. H., Sumertajaya, I. M., \& Sartono, B. (2021). Clustering of Commodity Inflation Pattern based on Estimated ARIMA Model. Journal of Physics: Conference Series, 1863(1), 0-9. https://doi.org/10.1088/1742-6596/1863/1/012058

Kustiari, R. (2017). Perilaku Harga Dan Integrasi Pasar Bawang Merah Di Indonesia Price Behavior and Market Integration of Shallots in Indonesia. Jurnal Agro Ekonomi, 35(2), 77-87.

Maharaj, E. A., D’Urso, P., \& Caiado, J. (2019). Time series clustering and classification. Boca Raton : CRC Press, Taylor \& Francis Group.

Montgomery, D. C., Jennings, C. L., \& Kulahci, M. (2015). Introduction Time Series Analysis and Forecasting. 671. John Wiley \& Sons, Inc., Hoboken, New Jersey.

Shi, C., Wei, B., Wei, S., Wang, W., Liu, H., \& Liu, J. (2021). A quantitative discriminant method of elbow point for the optimal number of clusters in clustering algorithm. Eurasip Journal on Wireless Communications and Networking, 2021(1). https://doi.org/10.1186/s13638-021-01910-w

T.Kousiga, \& Dr. R Shanmuga Vadiv. (2019). Hierarchical Clustering Algorithms in Data Mining. International Journal of Scientific Development and Research (IJSDR), 4(9), 1-3. http://www.waset.org/publications/10002625

Wijaya, S. U., \& Ngatini, N. N. (2020). Pengembangan Pemodelan Harga Beras di Wilayah Indonesia Bagian Barat dengan Pendekatan Clustering Time Series. Limits: Journal of Mathematics and Its Applications, 17(1), 51. https://doi.org/10.12962/limits.v17i1.5994 